\title{
A new species of Atheroides Haliday (Hemiptera, Aphididae) native to North America
}

\author{
Gary L. Miller', Andrew S. Jensen², Mark A. Metz', Robert R. Parmenter ${ }^{3}$ \\ I USDA, ARS, Systematic Entomology Laboratory, Beltsville, Maryland, USA 2 Department of Entomology, \\ Washington State University, Pullman, Washington, USA 3 Scientific Services Division, Valles Caldera National \\ Preserve (USDA), Jemez Springs, New Mexico, USA
}

Corresponding author: Gary L. Miller (gary.miller@ars.usda.gov)

Academic editor: R. Blackman | Received 11 June 2014 | Accepted 17 September 2014 | Published 4 November 2014

http://zoobank.org/9DD1F878-50DF-4BA6-9735-43392FD02ABF

Citation: Miller GL, Jensen AS, Metz MA, Parmenter RR (2014) A new species of Atheroides Haliday (Hemiptera, Aphididae) native to North America. ZooKeys 452: 35-50. doi: 10.3897/zookeys.452.8089

\begin{abstract}
We report and describe the first species of Atheroides Haliday presumed to be native to North America, collected at the Valles Caldera National Preserve, New Mexico, USA. We hypothesize its placement among the Siphini based on morphological, phylogenetic analysis and extend the distribution of the genus to the Holoarctic. We expand the key of the known Atheroides to include the new species and discuss the current hypotheses of the geographic distribution of the type species, Atheroides serrulatus Haliday.
\end{abstract}

\section{Keywords}

Valles Caldera National Preserve, Nearctic, cladistics, new species, Atheroides, Aphididae, Chaitophorinae, Siphini

\section{Introduction}

The Jemez Mountains in northern New Mexico, USA, constitute a "sky island" at the southern end of the Rocky Mountains of North America. This area now serves as a Pleistocene biological refugium, supporting high-elevation ecosystems left behind by the last retreating Ice Age 20,000 years ago (Goff 2009). Increasing aridity during the last 10,000 years has created arid grassland valleys around the Jemez Mountains, 


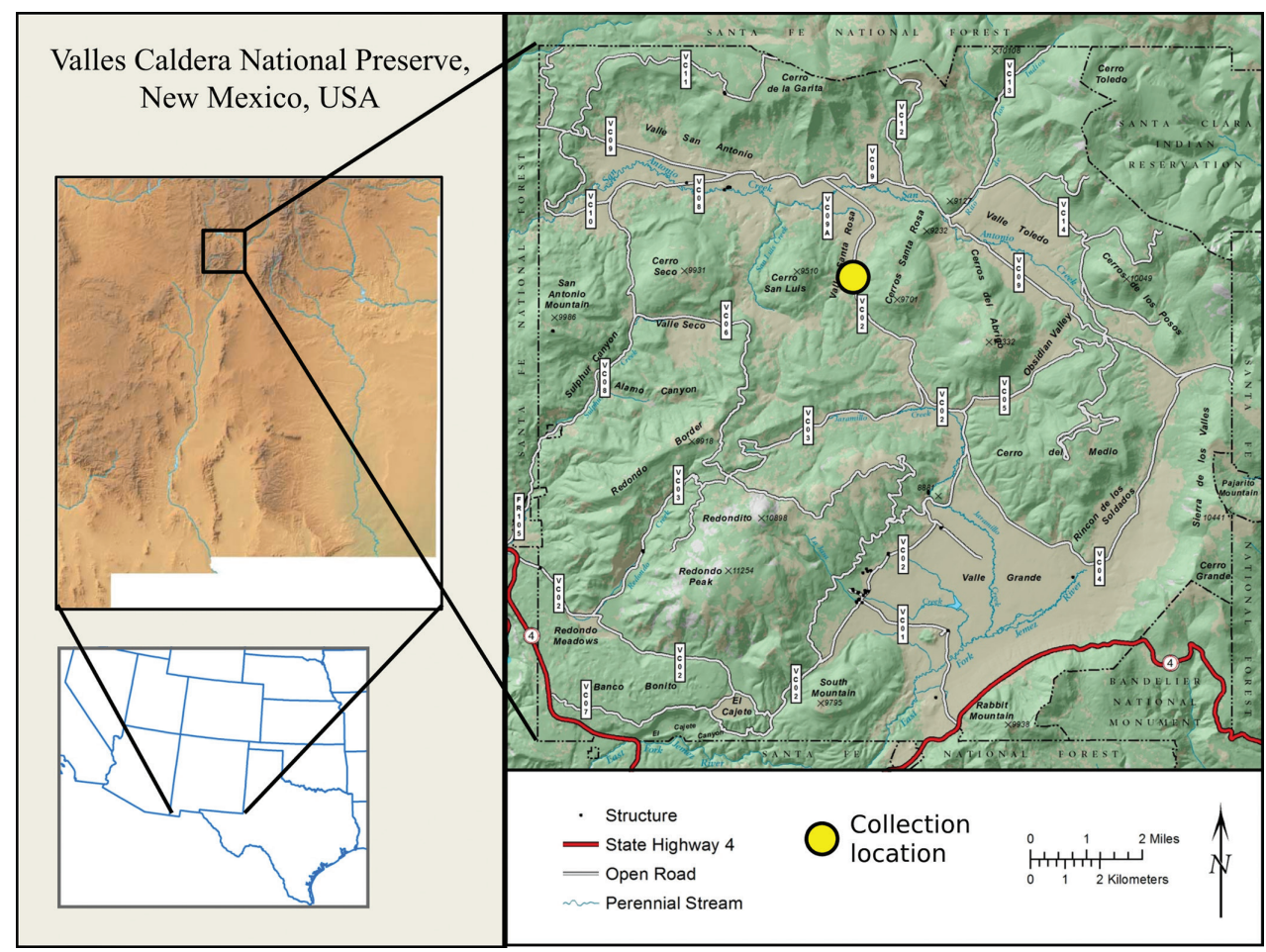

Figure I. Map of the Valles Caldera National Preserve, New Mexico, USA, showing collection location.

isolating the montane forested and meadow ecosystems from similar habitats in adjacent mountain ranges. In the center of the Jemez Mountains lies a super-volcano's caldera, which today encompasses the Valles Caldera National Preserve (VCNP) under the U.S. Department of Agriculture. As part of an inventory of the Preserve's natural resources, VCNP scientists and entomologists from the USDA's Systematic Entomology Laboratory began an extensive survey of the forests and valles. While producing numerous new distribution records for the state of New Mexico, no new insect taxa endemic to this ecosystem had been found. This work constitutes one of the first published accounts of a new species of insect collected at VCNP and unknown from any other locality. Remarkably the species is in a genus of aphids, Atheroides Haliday, 1839, with no known native, New World species. Because Atheroides prior to this discovery appeared to have a Palaearctic distribution except for the North American adventive, A. serrulatus, this account may represent the first support for a geologic refuge.

Atheroides is part of the tribe Siphini Mordvilko, 1928, the most derived clade of the Chaitophorinae Mordvilko, 1909, and was treated extensively by Wieczorek (2009, 2010) and Wieczorek and Kajtoch (2011). The genus is considered to have a Palaearctic distribution. Although, the type species, A. serrulatus Haliday, 1839, has been collected in Canada, the remaining species are known only from the Palaearctic region. Because of this apparent disjunct distribution $A$. serrulatus was considered 
an adventive, albeit non-invasive, species to the New World (Richards 1972, Foottit and Richards 1993, Foottit et al. 2006). Compared with other members of Siphini, Atheroides can be distinguished by their elongate, narrow body and a semicircular tergite VIII that covers the cauda (Wieczorek 2010). Species of Atheroides are known to feed on grasses and sedges. Their long, flat bodies seem ideal for positioning themselves between blades of grass, and the blunt, apical segment of the rostrum is diagnostic for grass-feeding aphids (Wieczorek 2009). Species in the genus also live singly or in small colonies (Wieczorek 2009), so considering their semi-reclusive, inconspicuous habits there may be more species awaiting discovery. In this paper we report and describe the first species presumed to be native to North America; hypothesize its placement among the Siphini based on morphological, phylogenetic analysis; and unquestioningly expand the distribution of the genus to Holoarctic.

\section{Methods}

We follow the recommendations of Thompson and Mathis (1980) for the names of Haliday first appearing in Curtis 1837 in terms of availability, validity, and priority. After DNA extractions were obtained, we mounted the specimens in Canada balsam (Favret 2005) and deposited them in the U.S. National Aphid collection, located at the Henry A. Wallace Beltsville Agricultural Research Center, Beltsville, Maryland, USA.

We made observations with both stereo and compound microscopes at magnifications from 100-400x. We used a Visionary Digital BK Lab System ${ }^{\circledast}$ and SolMate Trans-Illumination System to take digital photographs of slide-mounted specimens with a Canon ${ }^{\circledast}$ EOS 5D Mark II DSLR camera. We montaged Z-stacks with Helicon Focus Pro ${ }^{\circledR}$. Illustrations were first hand-drawn using a Nikon ${ }^{\circledR}$ Eclipse E600 and a drawing tube. Final illustrations were rendered on Denril ${ }^{\oplus}$ multi-media vellum using Pigma ${ }^{\oplus}$ Micron $^{\circledast} 005$ and 01 technical pens. We performed digital image editing/enhancement/manipulation in the Gnu Image Manipulation Program (GIMP). Dimensions of structures in the description are reported in millimetres; for apterous viviparae the first measure is that of the holotype and the second that of the paratype; for oviparae ranges are followed by means in parentheses.

We approached the phylogenetic analysis with the assumptions that Siphini was monophyletic and part of the Chaitophorinae, that the species in question was undescribed, and that the new species belonged to Siphini. The phylogenetic question was the correct generic placement of the new species. We sampled taxa within Siphini so as to have all of the type species of the currently included genera (Wieczorek 2010; Wieczorek and Kajtoch 2011), and chose as the outgroup taxon the type species of Chaitophorinae. We included two species of each subgenus of Sipha, since support of a monophyletic Sipha requires further research (Wieczorek 2010; Wieczorek and Kajtoch 2011). Our entire taxon sample for testing the placement of the new species was: Chaitophorus leucomelas Koch, 1854 (type of Chaitophorinae); Atheroides serrulatus (type of Atheroides); Laingia psammae Theobald, 1922 (type of Laingia Theobald, 
1922); Sipha (Rungsia) maydis Passerini, 1860 (type of the subgenus Rungsia Mimeur, 1933); Sipha (Rungsia) elegans Del Guercio, 1905; Chaetosiphella berlesei (Del Guercio, 1905) (Sipha) (type of Chaetosiphella Hille Ris Lambers, 1939); Sipha (Sipha) glyceriae (Kaltenbach, 1843) (Aphis L., 1758) (type of Sipha); Sipha (Sipha) flava (Forbes, 1884) (Chaitophorus Koch, 1854); Caricosipha paniculata Börner, 1939 (type of Caricosipha Börner, 1939). We included in the cladistic matrix characters used previously by Wieczorek (2010) and Wieczorek and Kajtoch (2011) (Characters 1, 3, 5, 8, 9, 10, and 11 in this analysis), but could not use those author's other characters because they were either uninformative among the current taxa sampled, were for characters of other life stages and/or sexes, or we could not score them unambiguously. We considered the coded states of their character 7 ("dorsal cuticle: (0) reticular or spinulose structures present; (1) smooth") to be not homologous, so separated those features into two separate characters (Characters 6 and 7 in this analysis.). We introduced characters 0,2 , and 4 . As a part of character mining, we measured all body segments, leg segments, antennal segments and rostral segments on the exemplars of all taxa, and used these measures to calculate every combination of ratios among them. We plotted the distribution of the calculated ratios among all taxa on histograms to check for bi- or multimodal distributions. We removed all characters we could not score unambiguously or had overlap in quantitive measures/ratios. We weighted all characters equally and coded them as unordered. We preferred combinations of binary characters and nominal state coding over multistate characters. We performed preliminary phylogenetic analysis using the Parsimony Ratchet routine in Winona (5000 iterations per rep, 5 trees held per iteration, 1 character sampled, and remaining parameters set to default; Nixon 1999). We did not need multiple reiteration on a dataset of this size. We then conducted exhaustive searches (implicit enumeration) using TNT (Willi Hennig Society edition; Goloboff et al. 2008) to corroborate the preliminary tree hypothesis. We calculated Bremer values (Bremer 1988) in TNT from exhaustive searches of progressively longer suboptimal trees (increments of 1 step).

We stored the HT apterous adult female and two oviparous adults collected in Valles Caldera National Preserve in $95 \%$ ethanol at $-20{ }^{\circ} \mathrm{C}$, until the DNA extractions were performed. We extracted DNA non-destructively with Qiagen ${ }^{\oplus}$ 's Blood \& Tissue kits (Valencia, CA) using a technique described by Favret (2005). The extractions followed the "Purification of Total DNA Animal Tissues" protocol with a few modifications (Qiagen 2006). Firstly, instead of the whole insect being pulverized, we pierced the integument of the aphid using a minuten insect pin. Secondly, we allowed the initial cell lysis step to continue for 24 hours instead of the recommended 1-3 hours. This extra time allowed the specimens to clear for microscope slide mounting. We amplified the barcoding region of COI using the forward primer: C1-J-1490: 59-ATTCAACCAATCATAAAGATATTGG-39 and reverse primer: C1-N-2198: 59-TAAACTTCTGGATGTCCAAAAAATCA-39 (Hajibabaei et al. 2006). We sequenced the fragment of $\mathrm{COI}$ in both directions using these primers with Applied Biosystems BigDye kits, version 3.1, and read on an Applied Biosystems ${ }^{\bullet}$ sequencer. We assembled and aligned sequences with Sequencher ${ }^{\bullet}$ v. 4.7 . 


\section{Results}

We were able to resolve a total of 12 binary morphological characters to address the question of generic placement of the new species among the genera of Siphini. Description of characters and character states included in the analysis follow:

0. Ratio of the Entire Body Length to the Body Width Measured Side to Side Across the Siphunculi

0 Body length less than $3 \times$ width of body

1 Body length at least $3.5 \times$ width of body

Wieczorek (2009) diagnosis Atheroides as "elongate, slender, nearly linear" (except $A$. brevicornis Laing, 1920). We used a ratio of length to width to quantify the elongation and narrowness of the taxa since the total length among the taxa investigated does not vary considerably. The length of the body was taken from the frons to the terminus of tergite VIII, and the width of the body was taken at the level of the siphunculi so as to make it objectively repeatable. The new species shares the derived state with $A$. serrulatus and $L$. psammae.

\section{Number of Antennal Segments \\ $0 \quad$ Six \\ 1 Five}

A five-segmented antenna has long been considered a diagnostic feature of Siphini among aphid workers and was corroborated by Wieczorek (2010) through cladistic analysis. The new species shares the derived state with all the species of Siphini included in the analysis.

2. Ratio of Length of Dorsad Apical Seta of Antennal Segment III to Width of Antennal Segment III Measured at Middle

0 Seta length at least $1.3 \times$ width of antennal segment 3 at middle

1 Seta absent or seta length subequal or less than width of antennal segment 3

The new species is notable among Siphini in having short, sparse setae on the antenna, particularly antennal segment III. We used a ratio of the length of the most apical dorsal seta on antennal segment III to the width of antennal segment III at the middle of the segment since that width did not vary considerably among the taxa investigated. The new species shares the derived state with $A$. serrulatus.

3. Ratio of the Length of the Processus Terminalis to the Base of the Terminal Antennal Segment

0 Processus terminalis shorter or subequal in length to the base of the terminal antennal segment

1 Processus terminalis at least $1.5 \times$ longer than the base of the terminal segment 
The ratio of the lengths of the base of the terminal antennal segment and the processus terminalis is used extensively among aphid taxa for genus and species level identification. This character is stable among taxa in the analysis - autopomorphic for Chaetosiphella berlesei - so is uninformative in this tree hypothesis, but is left in for the benefit of future work in the group.

\section{Ratio of Hindfemur Length to Midfemur Length}

0 Hindfemur length less than $1.5 \times$ length of midfemur

1 Hindfemur length at least $1.6 \times$ length of midfemur

The new species is notable among Siphini in having a short femur on the fore- and midlegs, particularly as compared to the femur of the hindlegs. The new species shares the derived state with $A$. serrulatus.

5. Shape of the Setae on the Dorsum of the Body

0 Dorsal setae almost exclusively acuminate

1 Dorsal setae scale-like, denticulate, and/or flabellate

The new species shares with other species of Atheroides the presence of non-acuminate setae throughout the body surface. The setae of the dorsum are characteristic of this diagnostic feature. The new species shares the derived state with $A$. serrulatus.

\section{Denticulate or Spiculate Cuticle Covering Most of Body}

0 Absent

1 Present

The integument between setal sockets may have raised, densely-distributed extensions that can be acuminate or blunt, as opposed to smooth cuticle. The derived state of this character does not support any monophyletic group resolved in the tree hypothesis.

\section{Dorsal Cuticular Surface Wrinkles and Folds}

0 Absent

1 Present

The new species shares with other species of Atheroides the presence of wrinkles and/or folds throughout the dorsal cuticle of the body reminiscent of the surface of the human brain. The new species shares the derived state with $A$. serrulatus.

8. Position of the Base of the Siphunculi

0 On abominal segment VI

1 On abdominal segment $\mathrm{V}$ 
The primitive state among Aphididae is for the siphunculi to be positioned on tergite VI. Among most Siphini the position of the siphunculi is on tergite V. The tree hypothesis created from this analysis suggests that the derived state supports the monophyly of Siphini sans Caricosipha paniculata with a reversal in Laingia psammae.

\section{Orifice of Siphunculus}

0 Elevated above the surface of the abdomen on a tube

1 Flush with the surface of the abdomen or on a short mound of cuticle, not elevated by a tube

The primitive state among Aphididae is for the siphunculous to be in the form of a tube or cylinder such that the external orifice is elevated above the surface of the dorsum. The new species shares the derived state with all the species of Siphini included in the analysis except Caricosipha paniculatae.

\section{Posterior Margin of Tergite VIII}

0 Not expanded posteriorly, cauda visible in dorsal view

1 Expanded posteriorly hiding cauda mostly or completely from dorsal view

The new species shares with the derived state with Atheroides serrulatus and Laingia psammae.

\section{Shape of cauda}

0 Constricted basally or subbasally creating an apical knob

1 Broadly rounded, truncate, or emarginate

The new species shares with other species of Atheroides the shape of the cauda, being broadly rounded, truncate, or emarginate as opposed to having a posterior elongation or a constriction with an apical knob. The new species shares the derived state with all the species of Siphini included in the analysis except Caricosipha paniculatae and the two species of Sipha (Sipha).

There were no missing or inapplicable characters in the matrix. The complete matrix is given in Table 1 . An exhaustive tree search resulted in a single, most parsimonious hypothesis of 14 steps $(\mathrm{CI}=85, \mathrm{RI}=88)$ (Fig. 3). There is no character evidence to support relationships among the two species of Sipha (Rungsia) and Chaetosiphella berlesei so we collapsed these nodes (Fig. 3). The data support a monophyly including the new species and A. serrulatus, the type species of Atheroides, (Bremer support of 4; Fig. 3).

We amplified and sequenced a 652 bp DNA fragment containing the barcoding region of the mitochondrial COI gene from the HT and two oviparous vouchers. Since all individuals produced sequences that were identical, only one sequence was submitted to GenBank (accession number KJ737374). We searched for matching sequences in GenBank and found multiple matches for Aphididae, but there were no sequences available for the taxa sampled in the phylogenetic analysis with enough overlap to warrant inclusion. 
Table I.Characters matrix.

\begin{tabular}{l|c|c|c|c|c|c|c|c|c|c|c|c}
\hline & \multicolumn{10}{|c}{ Character } \\
\hline Taxon & $\mathbf{0}$ & $\mathbf{1}$ & $\mathbf{2}$ & $\mathbf{3}$ & $\mathbf{4}$ & $\mathbf{5}$ & $\mathbf{6}$ & $\mathbf{7}$ & $\mathbf{8}$ & $\mathbf{9}$ & $\mathbf{1 0}$ & $\mathbf{1 1}$ \\
\hline Chaitophorus leucomelas Koch, 1854 & 0 & 0 & 0 & 0 & 0 & 0 & 0 & 0 & 0 & 0 & 0 & 0 \\
\hline Sipha (Rungsia) elegans Del Guercio, 1905 & 0 & 1 & 0 & 0 & 0 & 0 & 1 & 0 & 1 & 1 & 0 & 1 \\
\hline Sipha (Rungsia) maydis Passerini, 1860 & 0 & 1 & 0 & 0 & 0 & 0 & 1 & 0 & 1 & 1 & 0 & 1 \\
\hline Sipha (Sipha) flava (Forbes, 1885) & 0 & 1 & 0 & 0 & 0 & 0 & 1 & 0 & 1 & 1 & 0 & 0 \\
\hline Sipha (Sipha) glyceriae (Kaltenbach, 1843) & 0 & 1 & 0 & 0 & 0 & 0 & 0 & 0 & 1 & 1 & 0 & 0 \\
\hline Caricosipha paniculatae Börner, 1939 & 0 & 1 & 0 & 0 & 0 & 0 & 0 & 0 & 0 & 0 & 0 & 0 \\
\hline Laingia psammae Theobald, 1922 & 1 & 1 & 0 & 0 & 0 & 0 & 0 & 0 & 0 & 1 & 1 & 1 \\
\hline Chaetosiphella berlesei (Del Guercio, 1905) & 0 & 1 & 0 & 1 & 0 & 0 & 1 & 0 & 1 & 1 & 0 & 1 \\
\hline Atheroides vallescaldera sp. n. & 1 & 1 & 1 & 0 & 1 & 1 & 1 & 1 & 1 & 1 & 1 & 1 \\
\hline Atheroides serrulatus Haliday, 1839 & 1 & 1 & 1 & 0 & 1 & 1 & 1 & 1 & 1 & 1 & 1 & 1 \\
\hline
\end{tabular}

\section{Atheroides Haliday, 1839}

Atheroides Haliday 1837: 218 (Nomen nudum)

Atheroides Haliday, 1839: 189. Type species Atheroides serrulatus Haliday, 1839: 189

by subsequent designation (Kirkaldy 1906: 10) (Note: Laing (1920) incorrectly

designates $A$. serrulatus Haliday as the type species again subsequent to Kirkaldy).

Apteroides Mordvilko, 1929: 91. (Subsequent misspelling)

Corealachnus Paik, 1971: 3. Type species Corealachnus suwonensis Paik, 1971: 4 by

original designation.

\section{Atheroides vallescaldera Miller \& Jensen, sp. n.}

http://zoobank.org/DBF1845E-8DBC-4B1B-920B-4AD9F9197FF6

Diagnosis. This new species can be distinguished from other species in the genus by the following combination of characters: setae on the dorsum flabellate and dentate, and arranged in rows; dorsum sclerotized with rugose sculpturing; marginal setae of abdominal tergites I-VI easily visible, longer than width of hindfemur at middle, acuminate; empodial setae flat, but with base and apex of equal width, not spatulate.

Description (slide-mounted specimens). Apterous vivipara (Figs 4-11, Table 2) (n $=2$ ): Body at least 3 times longer than wide, dorsum rugose, dorsal setae on segments I-VII 0.018-0.058, mostly dentate and flabellate with some acuminate, arranged in rows, marginal setae acuminate, longer than width of hindfemur at middle, present on all abdominal segments. Head (Fig. 6) rectangular, flattened dorsoventrally and frons flat with bluntly pointed projections, one medial projection more prominent, rugose; setae acuminate on front and sides and denticulate (Fig. 8) dorsally; antennal tubercle undeveloped, basal antennal articulation flush with side of head; eyes slightly inset, eye outer margin almost flush with head margin, sometimes partially obscured 
Table 2. Morphometric data for apterous viviparae and oviparae of Atheroides vallescaldera sp. n.

\begin{tabular}{l|c|c|c|c}
\hline & \multicolumn{2}{|c|}{ A. vallescaldera sp. n. } & \multicolumn{2}{c}{$\begin{array}{c}\text { A. serrulatus (from } \\
\text { Wieczorek 2009, 2010) }\end{array}$} \\
\hline & Oviparae & Viviparae & Oviparae & Viviparae \\
\hline Body [mm] & N=8 & N=2 & N=6 & N=17 \\
\hline Antenna [mm] & $2.08-2.30$ & $2.07-2.21$ & $2.00-2.35$ & $1.70-2.20$ \\
\hline Antenna / Body [times] & $0.54-0.58$ & $0.53-0.55$ & - & - \\
\hline Ant. segm. III [mm] & $0.24-0.27$ & $0.25-0.26$ & 0.21 & 0.19 \\
\hline Ant. segm. IV [mm] & $0.17-0.19$ & $0.17-0.18$ & - & - \\
\hline Ant. segm. V base [mm] & $0.06-0.08$ & $0.07-0.07$ & - & - \\
\hline Ant. Segm. V base / Ant segm. III [times] & $0.07-0.09$ & $0.08-0.08$ & - & - \\
\hline Ant. segm. V processus terminalis [mm] & $0.41-0.53$ & $0.44-0.49$ & $0.50-0.55$ & $0.50-0.70$ \\
\hline Ant. segm. V processus terminalis / Ant. segm. III [times] & $0.07-0.09$ & $0.08-0.08$ & - & - \\
\hline Ant. segm. V processus terminalis / base [times] & $0.77-1.29$ & $0.43-0.45$ & - & - \\
\hline Ant. Segm. V / Ant. Segm. III [times] & $0.89-1.03$ & $1.00-1.05$ & $0.77-0.91$ \\
\hline Ant. Segm. V / Ant. Segm. IV [times] & $0.82-1.00$ & $0.89-0.92$ & $1.00-1.10$ & $1.10-1.30$ \\
\hline Ultimate rostral segm. [mm] & $2.07-2.58$ & $2.27-2.33$ & $3.00-3.25$ & $2.20-3.50$ \\
\hline Ultimate rostral segm. / its basal width [times] & $0.12-0.13$ & $0.12-0.13$ & $0.07-0.10$ & $0.07-0.10$ \\
\hline Ultimate rostral segm. / Ant. segm. V base [times] & $1.77-2.36$ & $2.10-2.15$ & - & - \\
\hline Ultimate rostral segm. / Ant. segm. III [times] & $1.43-1.79$ & $1.50-1.53$ & - & - \\
\hline Ultimate rostral segm. / Hind tarsus, 2nd segm. [times] & $0.66-0.76$ & $0.67-0.73$ & 0.69 & 0.69 \\
\hline Hind femur [mm] & $0.77-1.00$ & $0.83-0.98$ & 0.75 & 0.75 \\
\hline Hind tibia [mm] & $0.33-0.38$ & $0.37-0.37$ & - & - \\
\hline Hind tibia / Body [times] & $0.55-0.65$ & $0.62-0.62$ & - & - \\
\hline Hind tarsus, 2nd segm. [mm] & $0.26-0.29$ & $0.28-0.30$ & - & - \\
\hline Siphunculus width [mm] & $0.13-0.14$ & $0.13-0.14$ & - & - \\
\hline & $0.02-0.03$ & $0.02-0.03$ & - & - \\
\hline
\end{tabular}

dorsally, triommatidium outer margin projecting only as far as eye outer margin. Antenna (Fig. 5) 5-segmented, not reaching hind margin of prothorax, without secondary sensoria, antennal setae length usually subequal to width of corresponding antennal segment or less at middle of segment. Ultimate rostral segment (Fig. 7) with 2 pairs of primary setae and 1 pair of secondary setae. Basitarsi with 1 stout spine and 4 acuminate setae, one longer than basitarsus, the rest subequal to basitarsus; empodial setae flat, but base and apex of equal width, not spatulate (Fig. 10). Siphunculus flush with the surface of tergite $\mathrm{V}$, without any elevation above the surface of the cuticle, orifice surrounded by a thickened band of cuticle. Tergite VIII (Fig. 9) broadly rounded, extending posteriorly so that it covers cauda, with robust, acuminate marginal setae. Cauda indistinct, obscured by setae of tergite VIII. Anal plate slightly emarginate, genital slightly emarginate (Fig. 11) with numerous irregularly arranged setae. Morphometric data are in Table 2. 


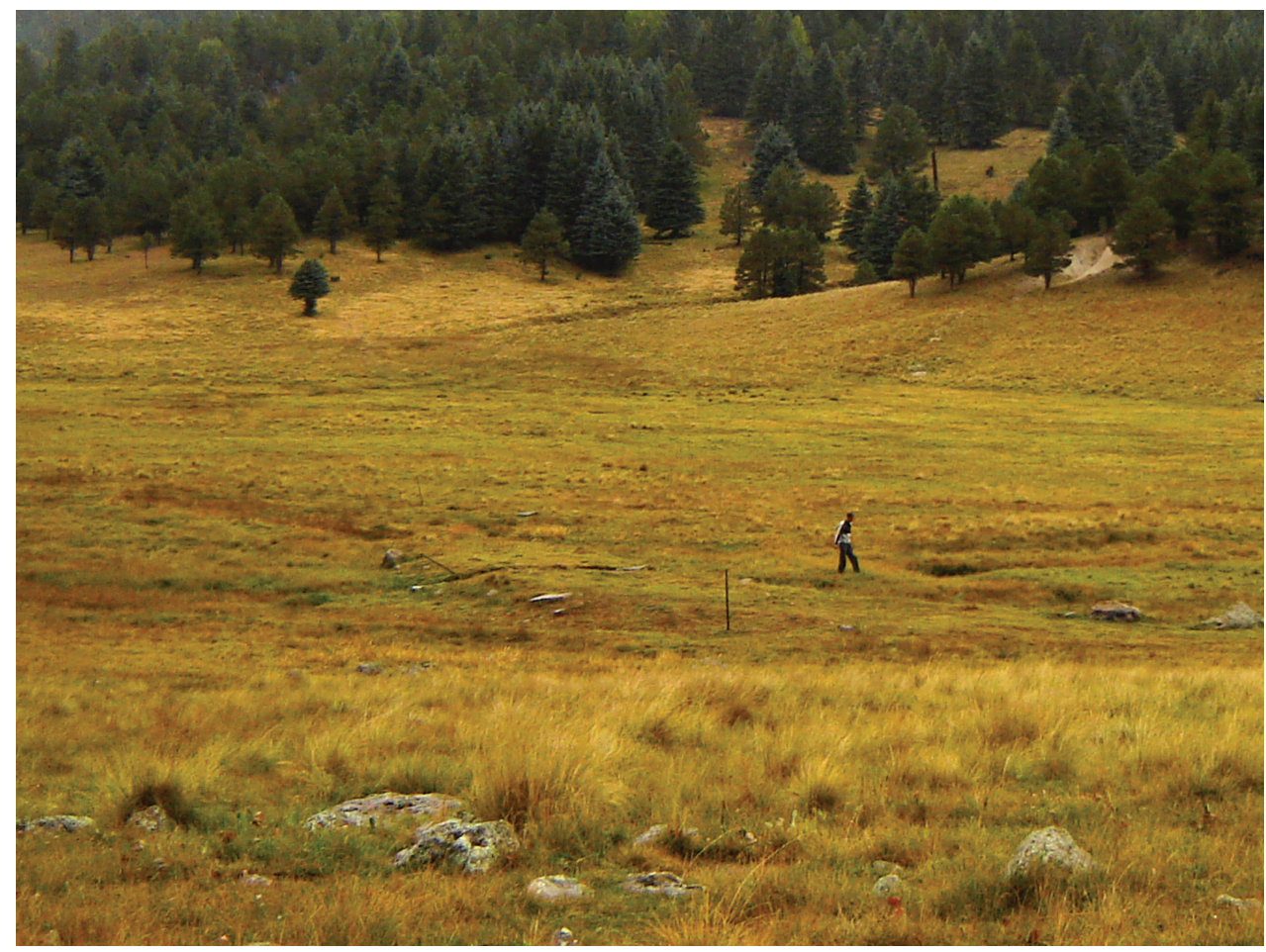

Figure 2. Second author in the habitat of the type locality for the new species along Santa Rosa Creek.

$D N A$ barcode (COI) for the holotype and one paratype contains 652 nucleotides (GenBank \# KJ737374):

GAACTTTATATTTTTTATTTGGAATTTGATCAGGACTAATTGGTTCTTCACTAAGAATTTTAATTCGATTAGAATTAAGACAAAT TAATTCAATCATTAATAATAATCAATTATATAATGTTATCATTACAATTCATGCATTTATTATAATTTTTTTTATAACTATACCAATTGTAATTGGTGGATTTGGAAATTGATTAATCCCTTTAATAATAGGATGCCCTGATATATCATTCCCACGATTAAATAATATTAGATTTTGAATACTTCCACCAGCATTAATATTTATAATTATAAGTTTTATAATTAATAATGGAACAGGAACAGGATGAACAATTTACCCCCCTCTATCTAACAATATTGCCCATAATAATATTTCTGTTGACTTAACAATTTTTTCTCTACATTTAGCAGGAATCTCATCAATTTTAGGAGCAATCAATTTTATTTGCACAATTATAAATATAATACCTAATAATATAAAAATTAATCAAATTCCTCTTTTCCCTTGATCTATTTTAATTACAGCAATCTTATTAATTTTATCTTTACCTGTATTAGCAGGTGCAATTACTATACTTTTAACTGATCGAAATCTTAATACTTCATTTTTTGATCCTTCAGGAGGTGGAGACCCTATCTTGTATCAACA

Alate vivipara and male: unknown. 


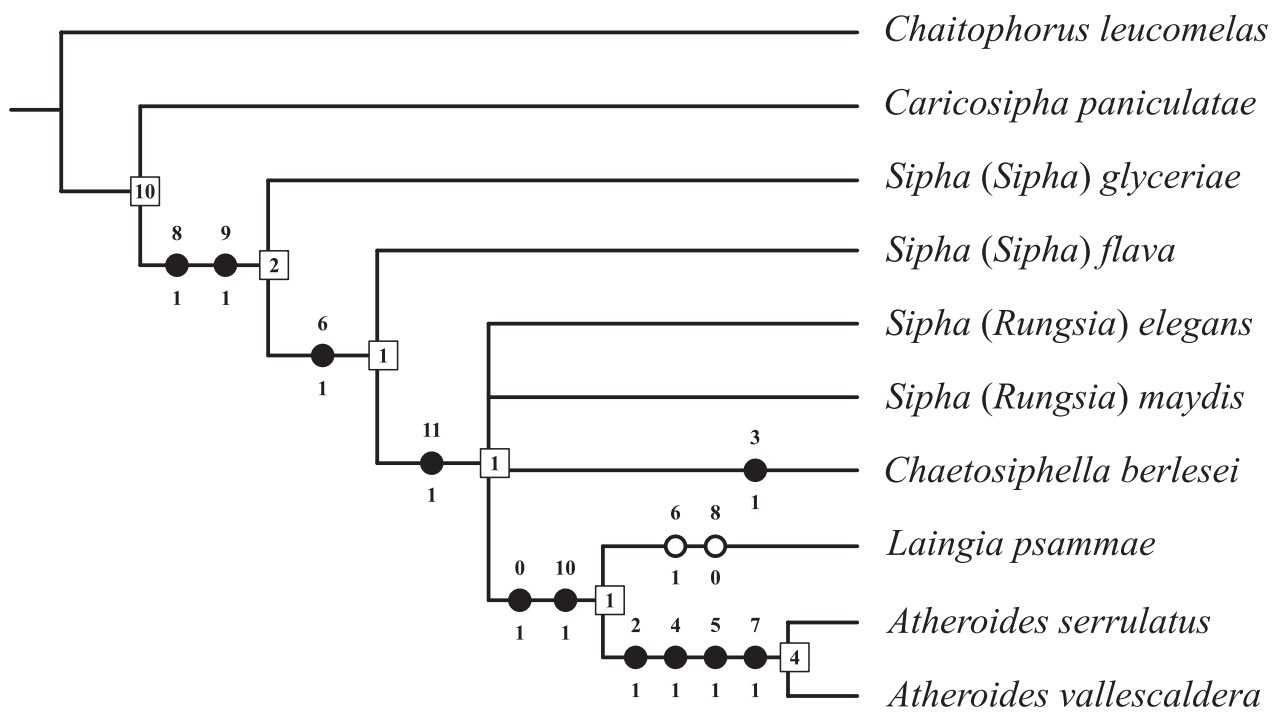

Figure 3. Single, most parsimonious tree of 14 steps $(C I=85, R I=88)$ resulting from an exhaustive search in TNT. Closed circles indicate unique forward changes. Open circles indicate either forward changes with homoplasy or reversals. Numbers on nodes in squares indicate Bremer support values for that node.

Ovipara $(\mathrm{n}=8)$ : Dorsal abdominal setae on segments I-VII 0.015-0.070. With 18-27 circular pseudosensoria on each hindtibia predominantly organized in pairs that are 8-shaped, others are single circles or triplets (conjoined pairs or triplets are still counted as single pseudosensoria). Otherwise similar to apterous vivipara. Morphometric data are in Table 2.

Etymology of specific epithet. The specific epithet, vallescaldera, is derived from the locality in which the specimens were collected, the Valles Caldera National Preserve, and should be considered a compound noun in apposition.

Specimens examined. Type-locality. USA: NEW MEXICO: Sandoval Co., near unit 12, lower Santa Rosa Creek watershed, a perennial stream tributary of the Rio San Antonio, 35.951; -106.521, VCNP\# 144, 23.ix.2010, 2,595m, A. Jensen coll., ex grass in open meadow next to Santa Rosa Creek, dominated by sedges, grasses, rushes and a variety of forbs (Fig. 2).

Holotype apterous vivipara (Figs 4-11): Slide-mounted in balsam USNMENT 00826485.

Original label: "New Mexico: Valles Caldera Nat'l Preserve Near Unit 1222 Sept. 2010 ex: grass in open meadow A. Jensen coll. SEL VCNP\#144 Balsam”

Paratypes: same data as holotype (1 apterous vivipara USNMENT 00826486, 8 oviparae USNMENT 00826487-89, USNMENT 00826480-84).

Host plants and habitat. Unknown bunch grass. All other known Atheroides spp. feed on a variety of grasses (Poaceae), sedges (Cyperaceae) and rushes (Juncaceae) (Wieczorek 2009). On the VCNP, there are 88 taxa of grasses, 31 taxa of sedges, and 

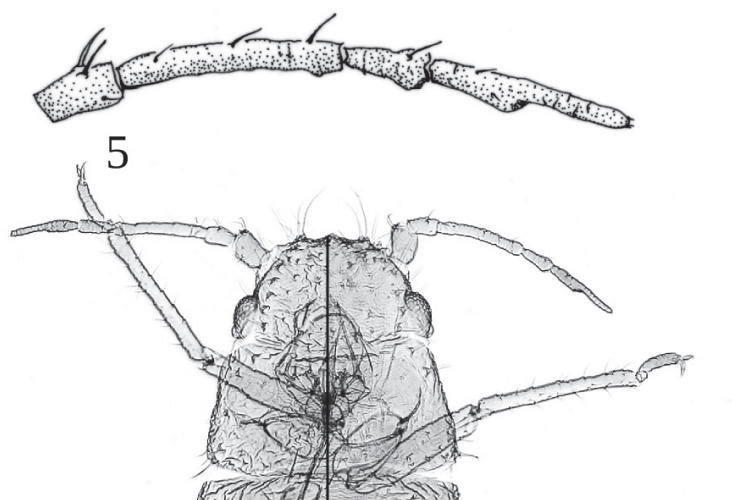

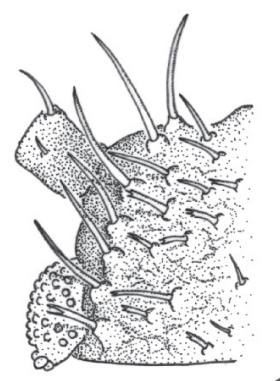

6

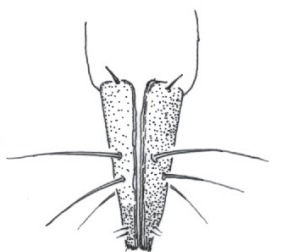

7
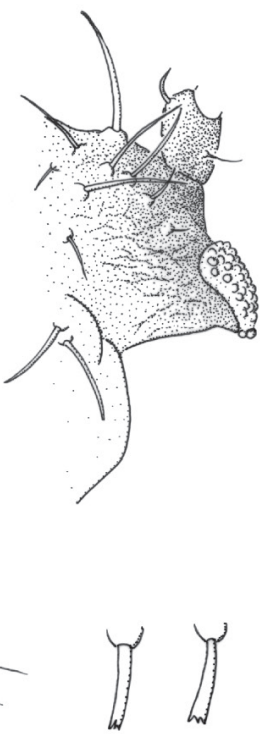

8

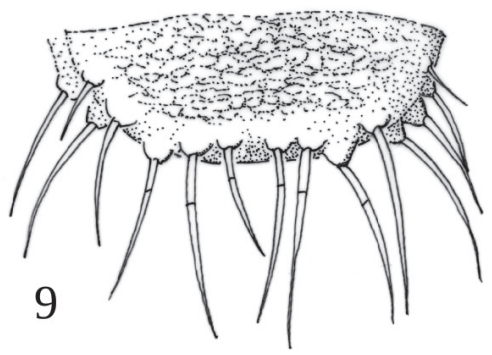

10

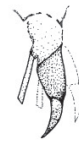

11

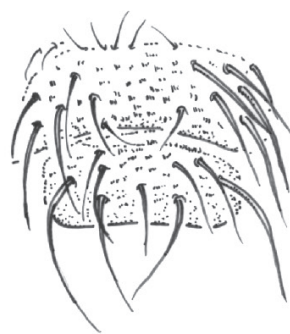

Figures 4-II. Atheroides vallescaldera n. sp. 4 holotype habitus (Left side focal planes from dorsum to middle. Right side focal planes from middle to ventral surface.) $\mathbf{5}$ antenna of apterous vivipara $\mathbf{6}$ head (left half dorsal, right half ventral) $\mathbf{7}$ ultimate rostral segments $\mathbf{8}$ examples of dorsal abdominal setae variation 9 tergite VIII (dorsal) $\mathbf{I} \mathbf{0}$ empodial setae I I anal and genital plates. (Scale indicated by $0.20 \mathrm{~mm}$ measure bars and corresponding figure number.).

11 taxa of rushes (includes subspecies and varieties). Among these plant taxa at the collection locale are common host plants of other Atheroides spp., including Deschampsia caespitosa, Phleum spp., Festuca spp., Carex spp., and Juncus spp. 
Key to the known species of Atheroides (apterous viviparae) (modified from Wieczorek 2009)

1 Setae on the dorsum of the body exclusively acuminate .............................2

1' Setae on the dorsum of the body acuminate, forked, dentate, and/or flabel-

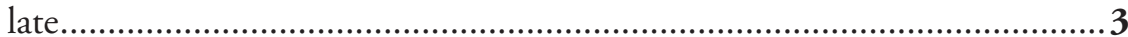

2 (1) Spinal setae very long, as long as or longer than marginal ones. Cauda covered by abdominal tergite VIII. On Deschampsia caespitosa

doncasteri Ossiannilsson, 1955

2' Marginal setae very long, longer than spinal ones. Cauda not covered by abdominal tergite VIII. On various grasses

birtellus Haliday, 1839

3 (2') Dorsum partially sclerotic without visible sculpture. Antennal segment III with 4-8 long setae. On Festuca ovina and Stipa splendens.

. karakumi Mordvilko, 1948

3' Dorsum sclerotic with visible, rugose sculpture. Antennal segment III with $0-4$ short setae. On various grasses ............................................................ 4

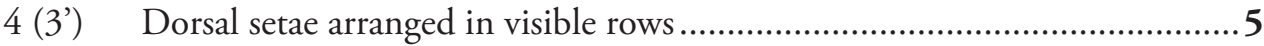

4' Dorsal setae not arranged in visible rows.............................................6

5 (4) Marginal setae of abdominal tergites I-VI short, hardly visible, rarely as long as width of hindfemur, dentate. Empodial setae spatulate, flat and broadened at apex serrulatus Haliday, 1839

5) Marginal setae of abdominal tergites I-VI easily visible, longer than width of hind femur at middle, acuminate (Fig. 4). Empodial setae flat, but with base and apex of equal width, not spatulate (Fig. 10) vallescaldera sp. $\mathbf{n}$.

6 (4') Body elongate, oval, 1.50-2.40 mm long. Antennae 4- or 5-segmented, $0.12-0.15$ times body length. Antennal segment I with 2 pointed and 1 dentate seta

brevicornis Laing, 1920

6. Body elongate, slender, nearly linear, $1.55-1.72 \mathrm{~mm}$ long. Antennae $5 \mathrm{seg}$ mented, 0.18-0.25 times body length. Antennal segment I with 1 erect fanshaped seta persianus Wieczorek, 2009

Key to the North American species of Atheroides (oviparae) (modified from Wieczorek 2010)

$1 \quad$ Hind tibiae with more than 30 pseudosensoria. Marginal setae of abdominal tergites I-VI short, hardly visible, rarely as long as width of hind femur, dentate. Empodial setae spatulate, flat and broadened at apex

serrulatus Haliday, 1839

1' Hind tibiae with less than 30 pseudosensoria. Marginal setae of abdominal tergites I-VI easily visible, longer than width of hindfemur at middle, acuminate (Fig. 4). Empodial setae flat, with base and apex of equal width, not spatulate (Fig. 10) vallescaldera sp. $\mathbf{n}$. 


\section{Discussion}

We have shown that $A$. vallescaldera is morphologically most similar to $A$. serrulatus among described Atheroides, yet there are clear morphological differences between the species. The facts that it is found in such an unusual geological feature as the Valles Caldera, and far from the known populations of $A$. serrulatus in Canada, suggest that $A$. vallescaldera is native to North America. This is a simpler explanation than the notion that two species of Atheroides have invaded North America, with one being unknown in the Palearctic yet establishing in an isolated and unique habitat in North America. Further, we suggest that it is possible that $A$. serrulatus is naturally Holarctic as opposed to adventive in North America.

The discovery of a new Atheroides species in the course of general aphid collecting using a beating tray technique (i.e. not specifically targeting cryptic grass feeders such as Atheroides) suggests that directed searching for Atheroides in North America may lead to discovery of additional native species. Future field work should include accurate species identification of host plants, searching a range of habitats including extremes of altitude, latitude, and precipitation, and detailed notes on microhabitats.

\section{Acknowledgments}

The authors thank A. Carmichael, Systematic Entomology Laboratory, Beltsville, MD, for assistance in DNA extraction and sequencing; and the Valles Caldera National Preserve for logistical and field collection support. We thank K. Wieczorek for examining specimens of $A$. vallescaldera and commenting on their identity prior to publication. We also thank the ZooKeys editor and two anonymous reviewers for their helpful comments and suggestions. Mention of trade names or commercial products in this publication is solely for the purpose of providing specific information and does not imply recommendation or endorsement by the USDA. The USDA is an equal opportunity provider and employer.

\section{References}

Börner C (1939) Neue Gattungen und Arten der mitteleuropaischen Aphidenfauna. Arbeiten über Physiologische und Angewandte Entomologie aus Berlin-Dahlem 6: 75-83.

Bremer K (1988) The limits of amino acid sequence data in angiosperm phylogenetic reconstruction. Evolution 42 (4): 795-803. doi: 10.2307/2408870

del Guercio G (1905) Contribuzione alla conoscenza delle Sipha Pass. Redia Giornale di Entomologia 2: 127-152; Pls xiii-xiv.

Favret C (2005) A new non-destructive DNA extraction and specimen clearing technique for aphids. Proceedings of the Entomological Society of Washington 107 (2): 469-470. 
Foottit RG, Richards WR (1993) The insects and Arachnids of Canada. Part 22. Genera of the Aphids of Canada (Homoptera: Aphidoidea and Phylloxeridae). Research Branch, Agriculture Canada Publisher, 766 pp.

Foottit RG, Halbert SE, Miller GL, Maw HE, Russell LM (2006) Adventive aphids (Hemiptera: Aphididae) of America North of Mexico. Proceedings of the Entomological Society of Washington 108(3): 583-610.

Forbes SA (1884) Thirteenth report of the State Entomologist on the noxious and beneficial insects of the state of Illinois, 1884. Annual Report of the State Entomologist of Illinois, second annual report of S.A. Forbes for the year 1883. Springfield, IL, 203+xxi pp.

Goff F (2009) Valles Caldera - A geologic history. University of New Mexico Press, Albuquerque, NM, 114 pp.

Goloboff PA, Farris JS, Nixon KC (2008) TNT, a free program for phylogenetic analysis. Cladistics 24 (5): 774-786. doi: 10.1111/j.1096-0031.2008.00217.x

Haliday AH (1837) A guide to an arrangement of British insects; being a catalogue of all the named species hitherto discovered in Great Britain and Ireland. In: Curtis J (Ed.) British entomology, 2nd ed. J. Pigot and Co., London, 294 pp.

Haliday AH (1839) New British insects indicated in Mr. Curtis Guide. Annals of Natural History 2: 161-240.

Hajibabaei M, Janzen DH, Burns JM, Hallwachs W, Hebert PDN (2006) DNA barcodes distinguish species of tropical Lepidoptera. Proceedings of the National Academy of Sciences of the United States of America 103: 968-971. doi: 10.1073/pnas.0510466103

Kaltenbach JH (1843) Monographie der Familien der Pflanzenläuse (Phytophthires). Roschütz, Aachen, 223 pp.

Kirkaldy GW (1906) Catalogue of the genera of the hemipterous family Aphidae, with their typical species, together with a list of species described as new from 1885 to 1905. Canadian Entomologist 38: 9-18. doi: 10.4039/Ent389-1

Koch CL (1854) Die Pflanzenläuse Aphiden, getreu nach dem Leben abgebildet und beschreiben. Nuremberg. Hefts I-IV: 1-134.

Laing F (1920) On the genus Atheroides Haliday (Aphidae). Entomologist's Monthly Magazine 6: $38-45$.

Mordvilko AK (1929) Food plant catalogue of the Aphididae of USSR. Works of Applied Entomology Leningrad 14: 1-101.

Mordvilko AK (1948) Aphidodea-tli ili rastiteInye wszi. In: Tarbinski A (Ed.) Opredelitel nasekomych evropejskoy casti USSR, Moskva, 187-226.

Nixon KC (1999) The Parsimony Ratchet, a new method for rapid parsimony analysis. Cladistics 15 (4): 407-414. doi: 10.1111/j.1096-0031.1999.tb00277.x

Ossiannilsson F (1955) A new European Atheroides (Hem., Hom., Aphid.) with synonymic notes on Atheroides hirtellus Hal. Entomologisk Tidskrift Argentina 76: 128-130.

Paik WH (1971) Corealachnus gen. nov. (Homoptera, Aphididae). Korean Journal of Entomology 1:3-5.

Passerini G (1860) Gli afidi. Con un prospetto dei generi ed alcune species nuove italiane. Ed. 2. Parma, 40 pp. 
Qiagen $^{\oplus}$ (2006) QIAGEN Supplementary Protocol: Purification of total DNA from insects using the DNeasy ${ }^{\oplus}$ Blood \& Tissue Kit. http://www.qiagen.com/resources/download. aspx?id=cabd47a4-cb5a-4327-b10d-d90b8542421e\&lang=en\&ver=1

Theobald FV (1922) A new aphid genus and species found in England. Bulletin of Entomological Research - London 12: 429-430. doi: 10.1017/S0007485300045089

Thompson FC, Mathis WN (1980) Haliday's generic names of Diptera first published in Curtis' A Guide to . . British Insects (1837). Journal of the Washington Academy of Sciences 70 (2): 80-89.

Wieczorek K (2009) A revision of the genus Atheroides Halidy, 1839 (Hemiptera: Aphididae: Chaitopherinae). Zoological Studies 48 (5): 693-708.

Wieczorek K (2010) A monograph of Siphini Mordvilko, 1928 (Homoptera, Aphidoidea: Chaitophorinae). Wydawnictwo Uniwersytetu Slaskiego, Katowice, 297 pp.

Wieczorek K, Kajtoch Ł (2011) Relationships within Siphini (Hemiptera, Aphidoidea: Chaitophorinae) in light of molecular and morphological research. Systematic Entomology, 36: 164-174. doi: 10.1111/j.1365-3113.2010.00550.x 